\title{
Assessment of Agro-Land Suitability for Rice (Oryza sativa L.) in Bhal Area of Gujarat Using GIS and Remote Sensing
}

\author{
Ranjan Kumar ${ }^{1 *}$ and G. R. Patel ${ }^{2}$ \\ ${ }^{1}$ College of Agricultural Engineering and Technology, Godhra, India \\ ${ }^{2}$ Department of Soil and Water Conservation Engineering, Godhra, India \\ *Corresponding author
}

\section{A B S T R A C T}

\section{Keywords}

Agro-land,

Suitability,

Evaluation, Yield,

Assess, Analytical

Hierarchy Process

(AHP), Multi

Criteria Evaluation

(MCE)

Article Info

Accepted:

10 March 2020

Available Online:

10 April 2020
Agro-land Suitability is a process of evaluation of agriculture land, which measures the degree of appropriateness of agricultural land for the use of particular crop that can best support that crop to be grown and maximise the yield. The aim of this study was to find the suitable land for rice so that yield of rice get maximise and fulfill the demand of growing population. The study was carried in Bhal region of Gujarat, where agriculture is preferred as mainstay but production get fluctuated due to improper selection of cultivated crop. Therefore, it is necessary to assess the suitable land for rice to achieve maximum potential of yield. There are various parameters such as LULC, Slope, Soil texture, Soil Moisture, Water holding capacity, $\mathrm{pH}$, Electrical conductivity, Nutrients (N, P, K) and Micronutrients (B, Fe, S, Mn, Zn, Cu) were used for the suitability assessment. These parameters were analysed, based on data availability, agronomist expert, Soil researcher and FAO guidelines to obtain the required result. An Analytical Hierarchy Process (AHP) and Multi Criteria Evaluation (MCE) technique was used to assess the suitability map of study area. A suitability map for Rice was obtained by overlaying the different parametric thematic suitable map in GIS Environment. The results of study shows that $13.55 \%$ of land is highly suitable $36.75 \%$ of land is moderately suitable $18.9 \%$ are least suitable and 30.8 $\%$ is not suitable for Rice. The research output was much helpful for the farmers of Bhal area in selection of Rice crop for particular land. Also, this research methodology helps many others researchers, in site selection, land use management, land use planning etc.

\section{Introduction}

Land is a potential source of natural resources like soil, water, nutrients, minerals, etc. for environmental activities (Bhagat and Zolekar, 2015). It is one of the most important natural resources, and maintaining its health is essential for meeting an ever increasing demand for food, fiber, fodder and fuel. It is a significant resource mainly for countries where their economy is based on agriculture. The population of the planet is dramatically increasing which causes an intensification and extensification of the agricultural sector (Yalew et al., 2016). Increasing population pressure and other natural factors like flood, 
drought, soil erosion and several other climatic disturbances are continuously hampering the growth rate of agricultural production in India and to meet the increasing demand for food, the farming community has to increase productivity. But in present situation where land is scarce, it is impossible to bring more area under cultivation to satisfy the growing demand, hence to increase food production and provide food security, crops need to be grown in areas where they are best suited.

According to ICAR (2010) report, about 120.40 million hectors land in India is affected by land degradations i.e. water and wind erosion (94.87million ha), water logging (0.91 million ha), soil alkalinity (3.71million ha), soil acidity (17.93 million ha), soil salinity (2.73 million ha) and mining and industrial waste (0.26 million ha) with annual soil losses of about 5.3 billion tones. Consequently, the area under non-agricultural uses increased by $11 \%$ in last decade whereas cultivable land and net sown area declined by $0.8 \%$ and $0.7 \%$ respectively (Agricultural census, 2012-13). The State of Food Insecurity in the World, 2015 report, 194.6 million people are malnourished in India. By this measure India is home to a quarter of the malnourished population in the world. It means that 17 per cent of Indians are still in starving condition to lead a productive life. In fact, one-quarter of the world's malnourished people lives in India, more than in all of SubSaharan Africa. Thus India has to make optimum utilization of the available land resources to satisfy its needs.

Agro-land suitability is the solution to mitigate from the situation to meet the increasing demand of population. Suitability analysis helps in selection of proper crops for specific area. Therefore, the knowledge of the land characteristics is essential for planning for optimal land use and sustainable development. These characteristics determine the land qualities information to incorporate different land attributes that differ spatially. To identify the best suitable land use, geographical information system (GIS) has proved to be the most suitable tools.

GIS can relate unrelated information by using location as the key index variable. Application of GIS can manage information and facilitate integration of multiple data layers with land suitability models. GIS-based AHP and multi-criteria evaluation technique is applied in the present study. The main advantage of this technique is that it can be done quickly utilizing the data processing and capabilities of GIS in the land use decision making process. Therefore, the results of this study will be useful with GIS-based land suitability analysis modelling in land-use planning and development plans in the future. Rice crop was selected for the study, as we all know that rice is the most consumed grains by people worldwide.

\section{Materials and Methods}

\section{Study area description}

Bhal region is located in land of opportunities, "Gujarat", on the south-west border of Saurashtra. It is a geographically backward region of Gujarat and is spread across the political boundaries comprising of three districts Bhavnagar, Ahmedabad and Anand districts. The region covers two revenue districts of Bhavnagar, and Ahmedabad on the left border of the Gulf of Khambhat. It lies between $21^{\circ} 45^{\prime}$ to $22^{\circ} 45^{\prime}$ $\mathrm{N}$ and $71^{\circ} 45^{\prime}$ to $72^{\circ} 45^{\prime} \mathrm{E}$ and covers an area of approximately $4520 \mathrm{Sq}$. Kms. The area receives precipitation through South-West monsoon from June to September. Annual rainfall in the region generally ranges between $500 \mathrm{~mm}$ to $700 \mathrm{~mm}$. Mostly the temperature ranges from $25^{\circ} \mathrm{C}$ to $30^{\circ} \mathrm{C}$. An 
approach has been undertaken to analyse the different sets of Parameters which are responsible for the dwindling nature of agricultural productivity in the Bhal region (Fig. 1).

\section{Methodology}

Assessment of land suitability for rice in the present study can be discussed as below:

Preparation of maps and data base

Selection of criteria (AHP and MCE)

Ranking of the different parameter on the basis of FAO guidelines and experts opinion.

Calculation of assigned ranks.

Preparation of normalised pairwise comparison matrix and calculation of weights.

Calculation of Scores.

The data information used for this study were collected from NBSS and LUP, Nagpur through BISAG in order to retrieve the properties like soil texture, soil depth, soil maximum water holding capacity etc. Total 144 Soil samples collected by random sampling method, were analysed in laboratory to notice the chemical properties of soil like $\mathrm{pH}, \mathrm{EC}, \mathrm{OC}, \mathrm{N}, \mathrm{P}, \mathrm{K}, \mathrm{B}, \mathrm{Fe}, \mathrm{S}, \mathrm{Mn}, \mathrm{Zn}$ and $\mathrm{Cu}$. The utilization of dataset procured from the soil sample for suitability analysis were utilized to set up the different suitable thematic maps with help of GIS programming with a system of IDW (tool in GIS).

\section{Expert opinions}

The utilization of dataset acquired from the soil sample for suitability analysis were utilized to generate the different thematic maps based on expert opinions. The studies like Bojorquez-Tapia et al., (2001), Joerin et al., (2001) and Kalogirou (2002) have utilized master conclusions to decide the different parameters to be analysed, assigned their rank and compute their weight. The outstanding researchers, experienced soil researcher, and journals with chauvinistic publications (with more perspectives and critics) of land suitability were chosen for the assessment as master about the standard utilization in this research. A questionnaire was structured with the soil researcher, agronomist, Farmers on farming exercises over the study area and their accuracy were verified. Around fourteen specialists have reacted and shared their useful information for this study. This information was implemented and analysed in software to obtain the satisfactory result. The important opinion by experienced researcher is based on logical and reasonable thinking with past experience. We are very thankful to the experienced research scientist. The rank given to all the Parameters for rice based on expert opinions and FAO guidelines, were shown in Table 1.

Based on the rank assigned for the rice, the pairwise comparison matrix was formed for the weight calculation, which is calculated by converting pairwise comparison matrix to normalised pairwise comparison matrix (NPCM). The consistency ratio was found to be less than 10 per cent, which shows that rank assignation for different Parameters was correct, then further processed (Fig. 2) in GIS to obtain the final suitability map. The final suitability map of rice is obtained by overlaying all thematic map layer in GIS according to calculated scores. The whole process of obtaining of suitability map is shown in the flow chart (Fig. 2.2).

$$
S=\sum_{i=1}^{n} W_{i} X_{i} \quad(\text { Eqn } 2.1)
$$

Where, $\mathrm{S}=$ total land suitability score

$\mathrm{W}_{\mathrm{i}}=$ weight of land suitability parameter

$\mathrm{X}_{\mathrm{i}}=$ sub-parameter score of $i^{\text {th }}$ land suitability parameter

$\mathrm{n}=$ total number of land suitability parameter 
Table.1 Parameter used for rice suitability calculation with their assigned rank

\begin{tabular}{|c|c|c|c|c|c|c|c|c|}
\hline Parameter & Slope & LULC & $\begin{array}{c}\text { Soil } \\
\text { texture }\end{array}$ & $\begin{array}{c}\text { Soil } \\
\text { depth }\end{array}$ & (MWHC) & EC & pH & SOC \\
\hline Rank & $\mathbf{1}$ & $\mathbf{3}$ & $\mathbf{2}$ & $\mathbf{4}$ & $\mathbf{5}$ & $\mathbf{7}$ & $\mathbf{8}$ & $\mathbf{6}$ \\
\hline $\begin{array}{c}\text { Nitrogen } \\
(\mathbf{N})\end{array}$ & $\begin{array}{c}\text { Phosphorus } \\
(\mathbf{P})\end{array}$ & $\begin{array}{c}\text { Potassium } \\
(\mathbf{K})\end{array}$ & $\begin{array}{c}\text { Boron } \\
(\mathbf{B})\end{array}$ & $\begin{array}{c}\text { Copper } \\
(\mathbf{C u})\end{array}$ & $\begin{array}{c}\text { Zinc } \\
(\mathbf{Z n})\end{array}$ & $\begin{array}{c}\text { Manganese } \\
(\text { Mn) }\end{array}$ & $\begin{array}{c}\text { Sulfur } \\
(\mathbf{S})\end{array}$ & $\begin{array}{c}\text { Iron } \\
(\mathbf{F e})\end{array}$ \\
\hline $\mathbf{9}$ & $\mathbf{1 0}$ & $\mathbf{1 1}$ & $\mathbf{1 2}$ & $\mathbf{1 3}$ & $\mathbf{1 4}$ & 15 & 16 & 17 \\
\hline
\end{tabular}

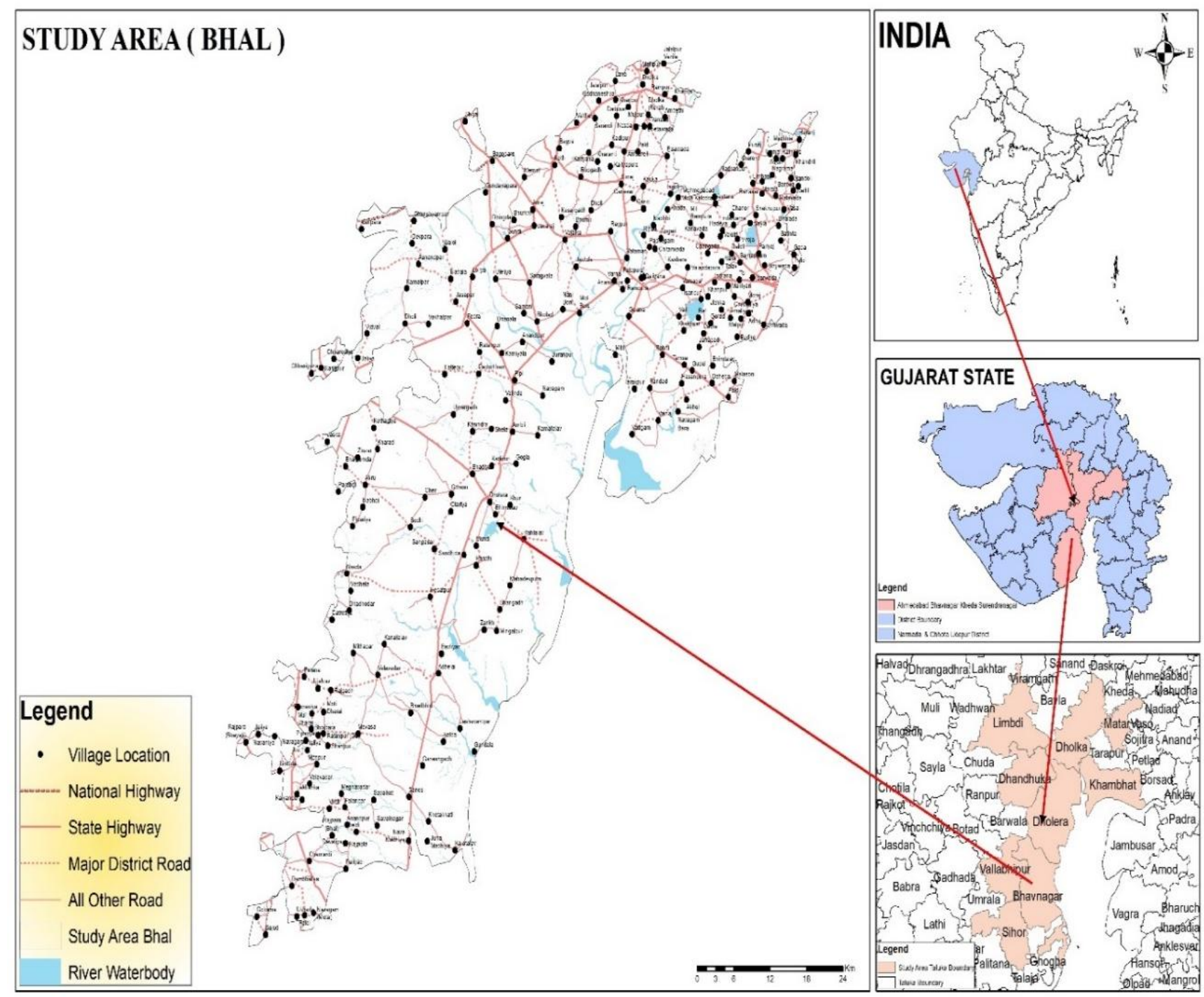

Fig.1 Location map of study area (Bhal) 


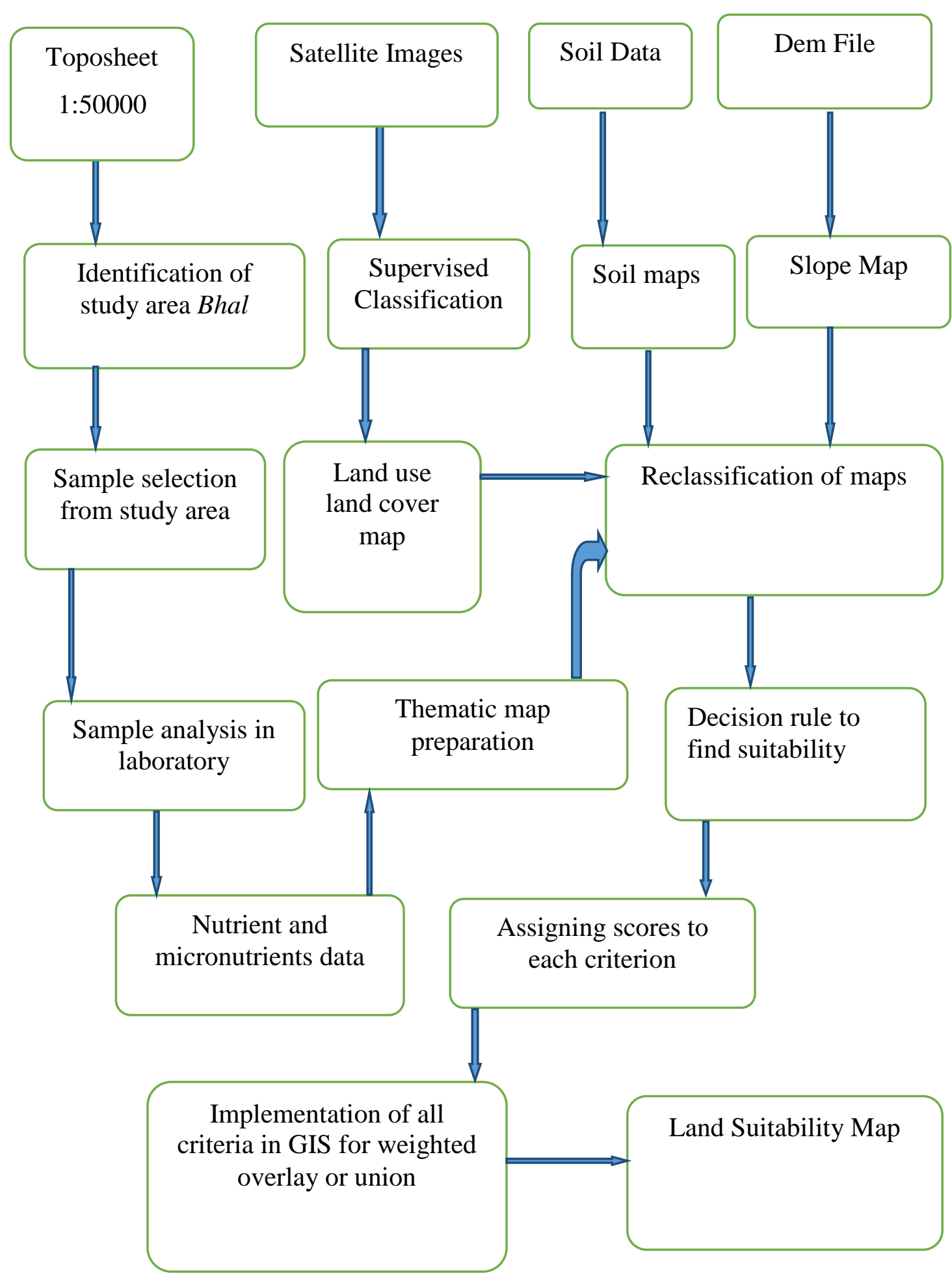

Fig.2 Schematic representation of methodology adopted for suitability analysis 


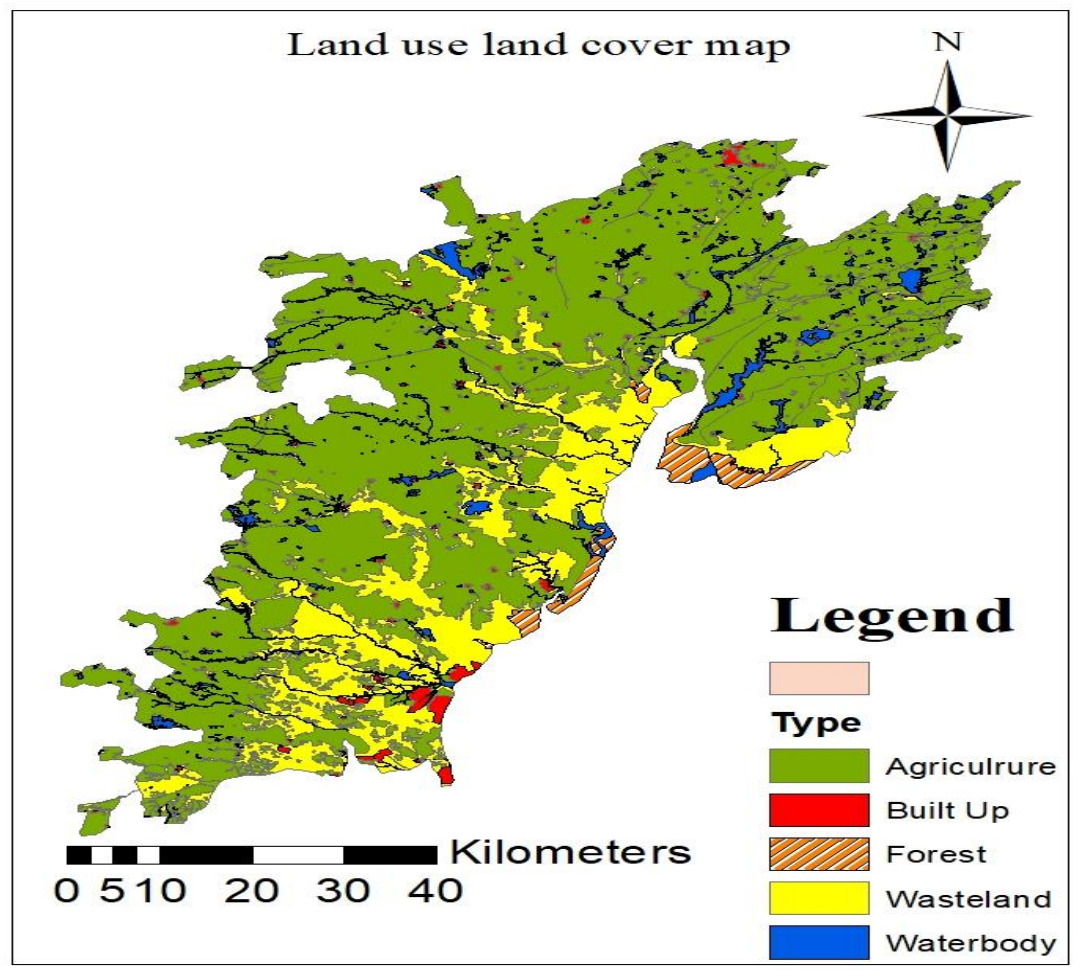

Fig.3 Land use land cover map

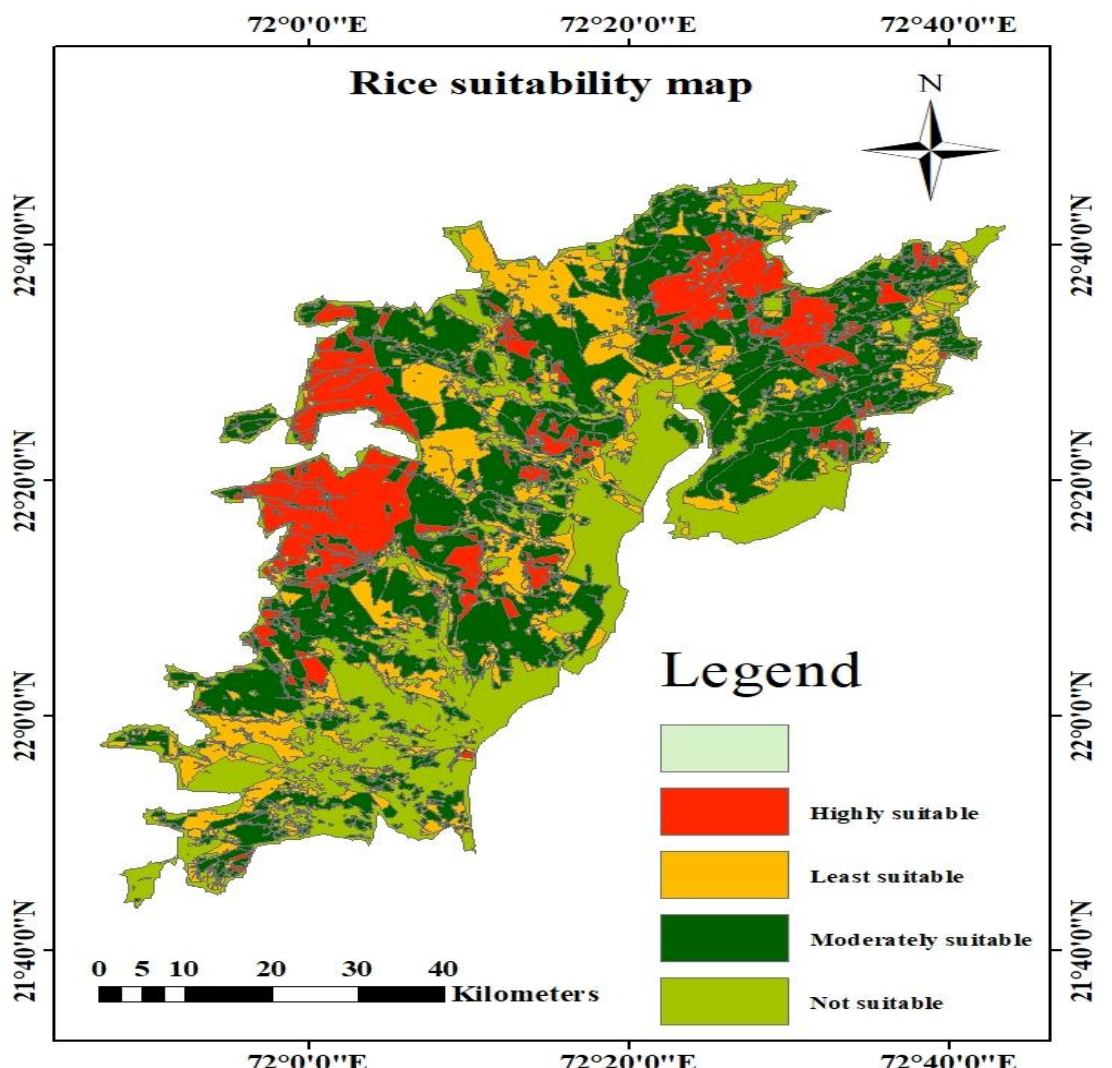

Fig.4 Land suitability map of rice 
The land use land cover map shows that major portion in the study area is agriculture i.e.71.42 per cent along with wastelands 20.48 per cent, water bodies 4.07 per cent, built up 2.14 per cent and forest area is 1.89 per cent as shown in the Figure 3 based on the information of land use land cover the suitability map of rice (Figure 4) were obtained.

The overall suitability of rice depends on the individual suitability characteristics properties of Parameters (Texture, Soil Depth, Slope, MWHC, EC, pH, Nutrients and Micronutrients). By considering the individual characteristics of each Parameters and integrating their effect the suitability map of rice was obtained (Figure 4).

The suitability map of the study area for rice was prepared in Arc Map 10.4 s. It is observed that about 30.8 per cent of total area was found to be not suitable, 18.9 per cent area of total study area was found to be least suitable, 36.75 per cent of total study area was found to be moderately suitable and 13.55 per cent of total study area was found to be highly suitable for rice.

The farmers of the Bhal region were facing problem of waterlogging as there is no proper drainage system is incorporated in the region. The rice crop get drowned at low lying area if the farmers have idea about the suitable land for rice as we have revealed out, using GIS, they can utilize the rice crop at proper place and obtain the optimum yield.

Rice is known to be one of the most consumed food in the world. Due to our research work farmer get benefitted and produce the maximum yield which indirectly may satisfy the population demand and also increase the Indian economy through Gross Domestic product (GDP).The objective of the result was to examine the suitability of land for rice crop using GIS and remote sensing. From the results obtained most of the study area lies in the slope range of $0-2.3 \%$ and were suitable for Rice and $71.42 \%$ consists of agriculture for cultivation of crops, also all other parameters were favorable for Rice cultivation. Out of $71.42 \%$ total agriculture land $36.75 \%$ of land area were found to be moderately suitable. Nutrients and micronutrients statistics were favorable for Rice cultivation. Further study can be practiced on this research basis for the suitability of other crop. It is very helpful in site selection, prioritization and land use management.

This research can also be utilized to find the suitability status for other crop like pulses, oilseed etc. at other cultivable land to maximize the yield and satisfy the future growing demands.

\section{References}

Abach, R. O., and Ngigi, M. M. (2016). Land suitability study for rice growing in Kisumu Country International Journal of Geomatics and Geosciences, 7(1), 33-42

Ambarwulan, W., Santoso, P. B., Sabiham, S., and Hikmat, M. (2016). Remote sensing and land suitability analysis to establish local specific inputs for paddy fields in Subang, West Java. Procedia Environmental Sciences, 33, 94-107.

Ayehu, G. T., and Besufekad, S. A. (2015). Land suitability analysis for rice production: A GIS based multi-criteria decision approach. American Journal of Geographic Information System,4(3), 95-104.

Bhagat, V. S., and Zolekar, R. B. (2015). Multi-criteria land suitability analysis for agriculture in hilly zone: Remote sensing and GIS approach. Computers and Electronics in Agriculture, 118, 
300-321.

Bojorquez-Tapia, L.A., Diaz-Mondragon, S., Ezcurra, E., (2001). GIS-based approach for participatory decision making and land suitability assessment. International Journal of Geographical Information Science 15(2), 129-151

FAO, 1976. A framework for land evaluation, Soil Bulletin 32. Food and Agriculture Organization of the United Nations, Rome, Italy

FAO, 1999. The state of food insecurity on the world. FAO, Rome.

FAO, 2006. Fertilizer and plant nutrition. Food and Agriculture Organization of the United Nations, Rome, Italy. bulletin 16.

FAO, WFP and IFAD. 2012. The State of food insecurity in the World 2012. Economic growth is necessary but not sufficient to accelerate reduction of hunger and malnutrition. Rome, Italy, $1-61$.

Joerin, F., Theriault, M., Musy, A., (2001). Using GIS and outranking multi-criteria analysis for land-use suitability assessment. International Journal of Geographical Information Science 15(2), 153-174.

Kalogirou, S. (2002). Expert systems and GIS: an application of land suitability evaluation. Computers, environment and urban systems, 26(2-3), 89-112.

Khan, R., Gurmani, A. R., Khan, M. S., and Gurmani, A. H. (2007). Effect of zinc application on rice yield under rice system. Pakistan Journal of Biological Sciences, 10(2), 235-239.

Perveen, F., Nagasawa, R., Uddin, M. I., and Delowar, H. K. (2007). Crop land suitability analysis using a multicriteria evaluation and GIS approach. In 5th International Symposium on Digital Earth. Berkeley, USA: The University of California, 1-8.

Sezer, I., and Dengiz, O. (2014). Application of a multicriteria decision-making approach for rice land suitability analysis in Turkey. Turkish Journal of Agriculture and Forestry, 38(6), 926934.

Yalew, S. G., Van Griensven, A., Mul, M. L., and Van Der Zaag, P. (2016). Land suitability analysis for agriculture in the Abbay basin using remote sensing, GIS and AHP techniques. Modeling Earth Systems and Environment, 2(2), 101.

Zhang, J., Su, Y., Wu, J., and Liang, H. (2015). GIS based land suitability assessment for tobacco production using AHP and fuzzy set in Shandong province of China. Computers and Electronics in Agriculture, 114, 202211.

\section{How to cite this article:}

Ranjan Kumar and Patel, G. R. 2020. Assessment of Agro-Land Suitability for Rice (Oryza sativa L.) in Bhal Area of Gujarat Using GIS and Remote Sensing. Int.J.Curr.Microbiol.App.Sci. 9(04): 1207-1214. doi: https://doi.org/10.20546/ijcmas.2020.904.143 